\title{
Spotted around the web: Mitochondria, police training, supporting scientists with disabilities
}

\author{
BY JILL ADAMS
}

23 JULY 2021

WEEK OF JULY $19^{\text {TH }}$

\section{Research roundup}

- Immune reactions to gluten are not linked to autism, according to a study that measured antibodies to a gluten component in pregnant women and their newborns. Autism Research

- A program that connects mental-healthcare practitioners to autism specialists for training and consultation improved providers' confidence in treating autistic people. Autism

- Differences in energy metabolism may play key roles in neurodevelopmental conditions; for instance, autistic people tend to have altered mitochondrial function. EBioMedicine

- An 8-year-old child with a developmental condition called AADC has improved after gene therapy, which was previously thought to work only for younger children. STAT

- A new method for assessing genetic risk factors, based on medical records of people born in Sweden, found a modest relationship between autism and attention deficit hyperactivity disorder and between autism and schizophrenia. Translational Psychiatry

- Police workshops that use behavioral skills training seem to be effective, according to tests that use actors to simulate autistic people's responses to an approaching officer. Read more about the interactions between autistic people and law-enforcement officers in Spectrum's 2020 special report. Journal of Autism and Developmental Disorders

- Alterations in the assembly and breakdown of proteins in the cytoplasm of cells are linked to neurodevelopmental conditions; far less is known about this activity in mitochondria and its ties to development. Journal of Neuroscience

- Mutations in the DSCAM gene seem to cause autism-like traits in mice via alterations in the activity of the neurotransmitter NMDA. Molecular Psychiatry

- Dysfunction of the autism-linked gene DYRK1A may inhibit the movement of protein 


\section{Spectrum | Autism Research News}

https://www.spectrumnews.org

precursors into mitochondria for further processing. Nature Communications

- More than one-third of the common gene variants linked to autism overlap spatially with those linked to attention deficit hyperactivity disorder. Journal of Child Psychology and Psychiatry

- Women with anorexia nervosa tend to score moderately on autism screens - higher than non-autistic people and lower than autistic people. Molecular Autism

- Autism traits, such as restricted and repetitive behaviors and social anxiety, may be heritable, a topic Spectrum covered in 2020. Autism Research

- The Autism Diagnostic Interview has been adapted for deaf children. Autism

\section{Science and society}

- Research institutions can support scientists with disabilities by creating inclusive policies and making technology accessible. The Scientist

- During the COVID-19 pandemic, researchers turned to primates to understand the disease, effectively removing those animals from previously planned research; now the United States is funding breeding efforts at national facilities to fill the gap. Nature

- Disability activists in New Zealand say that people with autism or attention deficit hyperactivity disorder encounter delays in care because they're viewed as needing mental health treatment. NZ Herald 